\title{
Syringo-peritoneal Shunt for Syringomyelia Due to Extensive Adhesive Arachnoiditis: A Case Report
}

\author{
Kyohei KIN, ${ }^{1}$ Takao YasuHARA, ${ }^{1}$ Atsuhiko TOYOSHIMA, ${ }^{1,2}$ and Isao DATE ${ }^{1}$ \\ ${ }^{1}$ Department of Neurological Surgery, Okayama University Graduate School of Medicine, \\ Okayama, Okayama, Japan \\ ${ }^{2}$ Shin-Aikai Spine Center, Katano Hospital, Katano, Osaka, Japan
}

\begin{abstract}
Adhesive arachnoiditis (AA) is a chronic inflammation inside the dura and remains one of the most challenging diseases. We describe a case of treatment-resistant extensive AA that offers insight into surgical treatment selection. The patient had a 2-year history of progressive spastic gait and was diagnosed with syringomyelia caused by extensive AA. Although syringe-subarachnoid and subarachnoid-subarachnoid shunting resulted in recurrence within a short period, syringoperitoneal shunting improved the symptoms and there was no recurrence. This case suggests that syringo-peritoneal cerebrospinal fluid (CSF) shunt drainage, which has previously been considered a further step, may be a first-surgery option for extensive AA.
\end{abstract}

Keywords: adhesive, arachnoiditis, shunt, syringomyelia

\section{Introduction}

Adhesive arachnoiditis (AA) is a chronic inflammation inside the dura that affects the meninges and results in fibrosis. It is caused by various factors, including previous spinal surgery, trauma, infection, and spinal injection of substances such as anesthetics or oil-based myelographic contrast materials. ${ }^{1)}$ Disturbance of cerebrospinal fluid (CSF) flow caused by AA leads to syringomyelia or tethering., ${ }^{2,3)}$

It is recommended that cases of syringomyelia with progressive symptoms undergo surgical treatment to reduce the syrinx and to stabilize the neurological status. ${ }^{2)}$ Various surgical methods have been reported, and shunt placement is one of the options. ${ }^{2,4,5)}$ There are various shunt procedures, such as subarachnoid-subarachnoid shunt, syringo-subarachnoid shunt, and syringo-peritoneal shunt. However, no criteria have been established governing which shunt procedures are appropriate for which situations.

Received July 3, 2020; Accepted December 7, 2020

Copyright@ 2021 The Japan Neurosurgical Society This work is licensed under a Creative Commons AttributionNonCommercial-NoDerivatives International License.
We present a case of huge syringomyelia due to extensive AA in which syringo-peritoneal shunt was more effective than intrathecal shunt. This case suggests that syringo-peritoneal CSF shunt drainage, which was previously considered a further step, is worth consideration as the first-choice treatment for extensive AA.

\section{Case Report}

An 11-year-old girl presented to our department with a 2-year history of progressive spastic gait. She had a history of congenital hydrocephalus and had been treated with external drainage. During this external drainage treatment period, she suffered from severe bacterial meningitis. The hydrocephalus and meningitis were eventually well controlled and she had been living at home independently.

Magnetic resonance imaging (MRI) showed a huge syrinx formation extending from the $\mathrm{C} 7$ to L2 level (Figs. 1A-1C). No evidence of hindbrain herniation was detected. Contrast-enhanced computed tomography and MRI did not indicate any abnormalities that could cause a syrinx. The subarachnoid space disappeared from C7 to the conus medullaris level and appeared to be unaffected from the rostral of the C7 level and the caudal of the conus medullaris (Figs. 1D and 1E). 

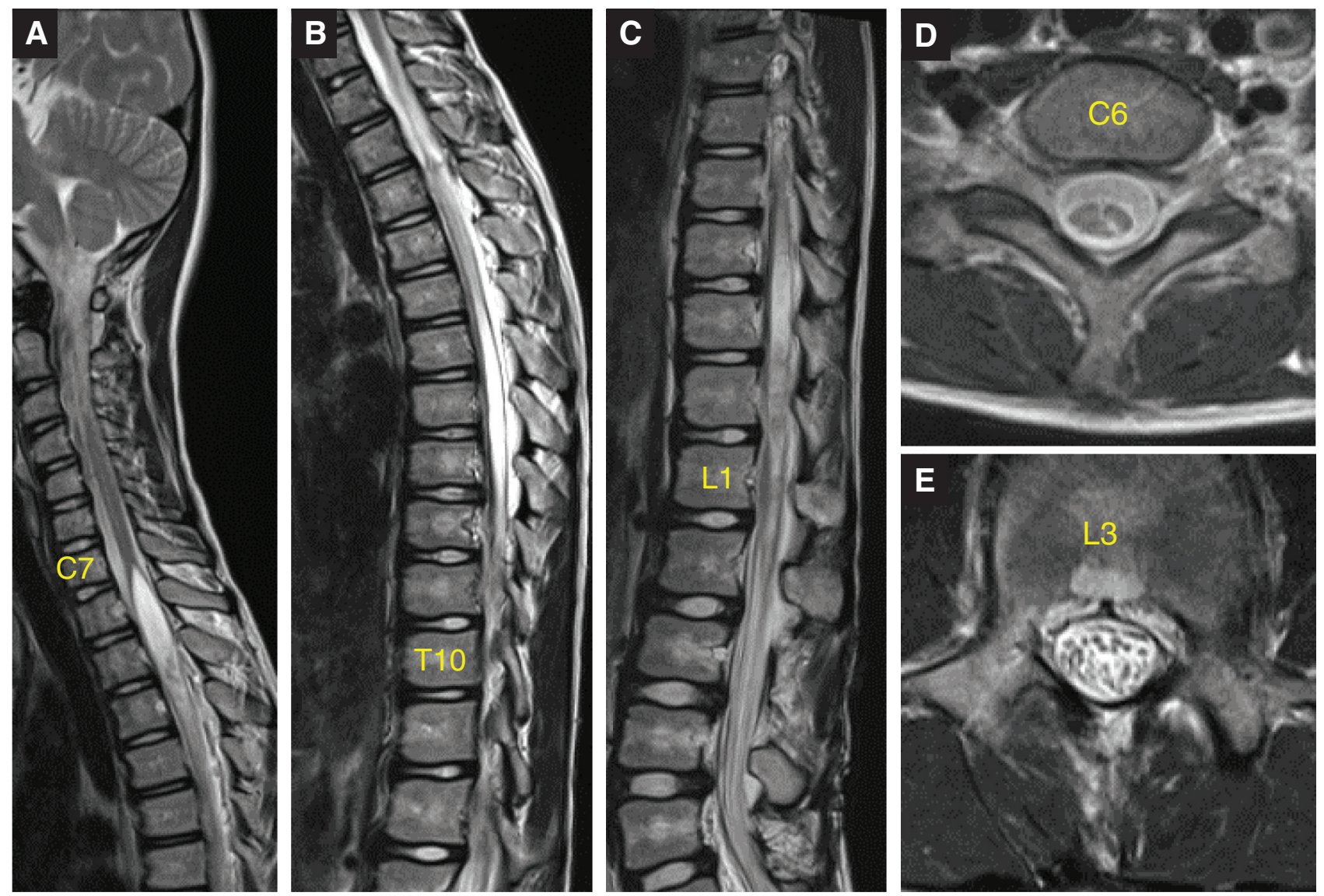

Fig. 1 Preoperative sagittal T2-weighted MRI (A-C) demonstrating a huge syrinx from the C7 to L2 level. Preoperative axial T2-weighted MRI at C6 (D) and L3 (E). These images suggest a normal subarachnoid space from the rostral of the $\mathrm{C} 7$ level to the caudal of the conus medullaris. MRI: magnetic resonance imaging.

Based on these findings and her episode of meningitis, she was diagnosed with syringomyelia caused by extensive AA. We speculated that CSF would be managed by drainage from the affected lesion to the normal subarachnoid space, which was the rostral side of the $\mathrm{C} 7$ level and the caudal side of the conus medullaris. Accordingly, a syringe-subarachnoid shunt from the syrinx to the lower cervical level (for draining CSF to the intact region) and a subarachnoid-subarachnoid shunt from the lower cervical level to the cauda equina level (for sharing drained CSF within intact regions) were placed. During this operation, the thickened arachnoid, which was consistent with our diagnosis, was detected (Fig. 2A). Pia, arachnoid, and CSF looked normal at the C5/6 and L2 levels which were speculated to be unaffected regions. Postoperative MRI showed a reduction of the syrinx (Figs. 2B-2D), and the spasticity of the bilateral lower extremities was gradually improved. Weakness of the bilateral quadriceps muscle and the tibialis anterior muscle, which seemed to be masked by spasticity preoperatively, appeared. Rehabilitation improved the weakness, and she was able to walk with a cane.

Weakness of the bilateral quadriceps muscle and the tibialis anterior muscle gradually worsened 1 year after the surgery. MRI revealed that the syrinx had enlarged (Figs. 3A and 3B). Additionally, CSF retention was found at the dorsal area of the cauda equina where the tip of the shunt tube was located (Figs. 3B-3D).

The shunt tubes were not clogged because CSF retention was found at the dorsal area of the cauda equina where no CSF retention was identified before the first surgery. Therefore, it was speculated that CSF was not well managed within the intra-arachnoid space, and drainage to the extradural space appeared necessary. Thus, syringe-peritoneal shunt placement was planned for the second operation. The proximal end of the shunt was inserted through the small myelotomy at the T9 level and the distal end was connected to a medium-pressure valve (Medtronic, Goleta, CA, USA) and a peritoneal catheter. Postoperative MRI showed the diminished 

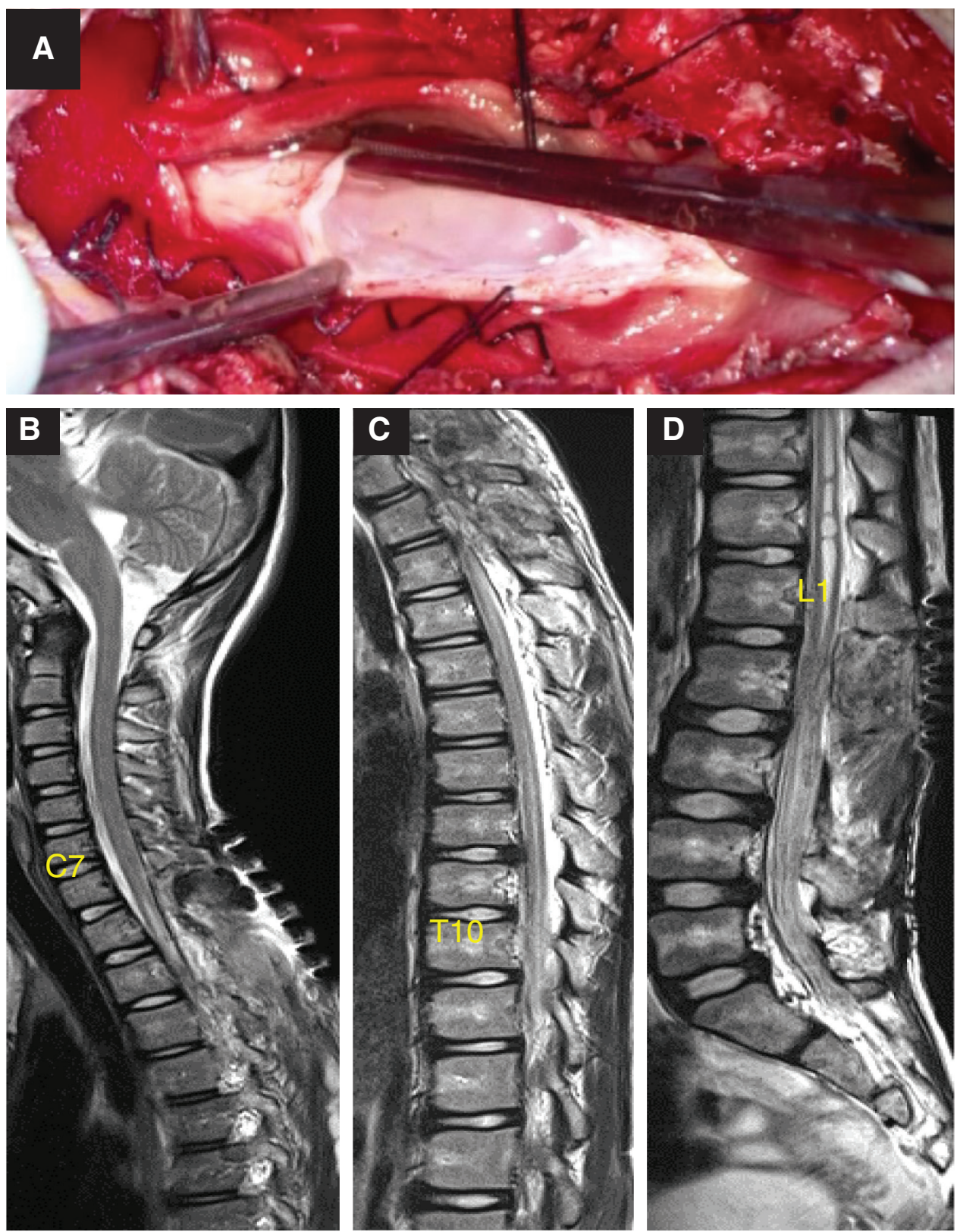

Fig. 2 (A) Intraoperative photograph of the first operation after dura opening. The whitish thickened arachnoid was identified, which is consistent with the diagnosis of AA. (B-D) Postoperative sagittal T2-weighted MRI shows shrinkage of the syrinx. AA: adhesive arachnoiditis, MRI: magnetic resonance imaging.

size of the syrinx (Figs. 4A-4C) and her symptoms improved again. After rehabilitation, she was discharged and able to live at home independently. At 2 years post-surgery, she could walk with a cane and MRI showed that the syrinx had not grown larger.

\section{Discussion}

We reported a case of huge syringomyelia due to AA in which a syringo-peritoneal shunt was more effective than an intrathecal shunt. Although selection of the type of shunt procedure has often been discussed, ${ }^{6-10)}$ it remains unsolved question. The experience from this case may provide us with some insight on this point.

Despite advances in surgical skills, treatment of syringomyelia due to AA remains a major challenge. ${ }^{2,11}$ Various surgical treatments have been reported and the ideal treatment remains controversial. ${ }^{2,12-15)}$ Restoration of the spinal subarachnoid space and CSF flow with arachnoidolysis and 

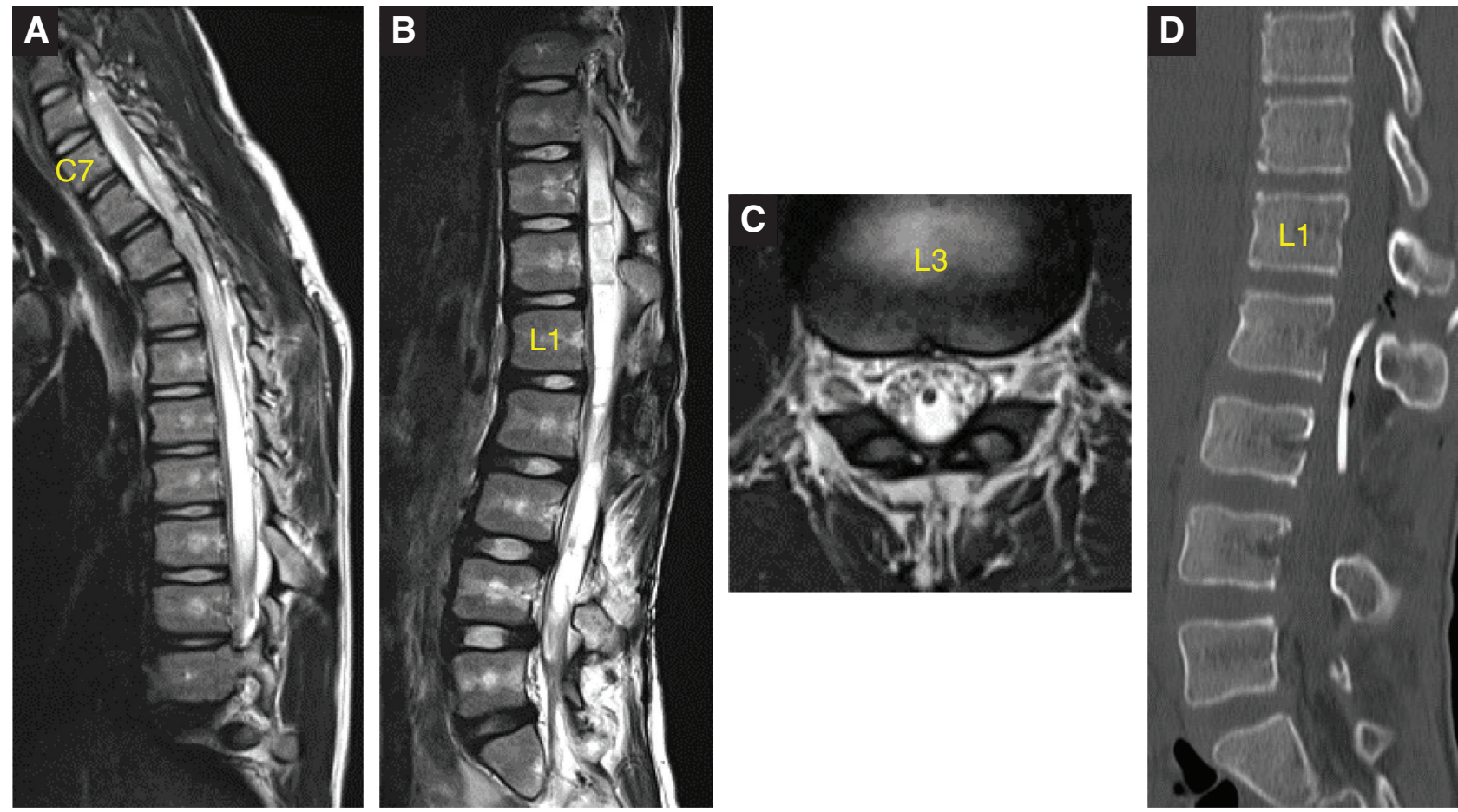

Fig. 3 T2-weighted MRI (A-C) and computed tomography imaging (D) just before the second operation. Sagittal T2-weighted MRI shows the enlarged syrinx (A and B). CSF retention was found to have accumulated at the dorsal side of the cauda equina (B and C) where the tip of the shunt tube was located (D). CSF: cerebrospinal fluid, MRI: magnetic resonance imaging.
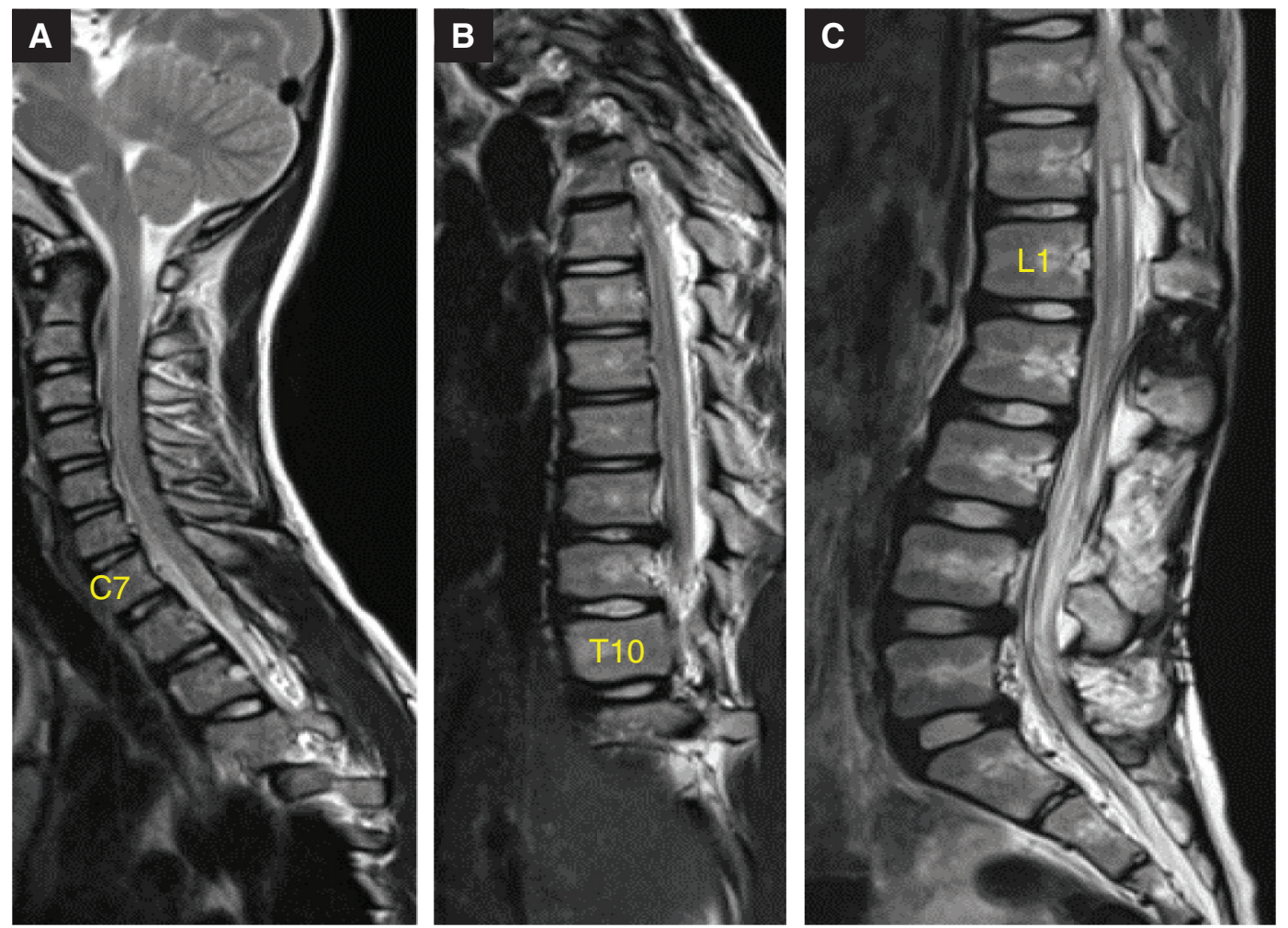

Fig. 4 (A-C) Postoperative MRI confirmed the improvement of the syrinx. MRI: magnetic resonance imaging. 
Table 1 Pons and cons of treatment for syringomyelia due to extensive adhesive arachnoiditis

\begin{tabular}{|c|c|c|c|}
\hline Surgery & & Pros & Cons \\
\hline \multicolumn{2}{|c|}{$\begin{array}{l}\text { Restoration of the spinal } \\
\text { subarachnoid space and CSF flow }\end{array}$} & Curative & $\begin{array}{l}\text { Technically difficult } \\
\text { Risk of spinal cord damage } \\
\text { Risk of further adhesion }\end{array}$ \\
\hline \multirow[t]{2}{*}{$\begin{array}{l}\text { Shunt } \\
\text { placement }\end{array}$} & Intrathecal shunt & $\begin{array}{l}\text { Technically easy } \\
\text { Restoration of CSF flow inside the dural sac }\end{array}$ & Difficult to predict the shunt effect \\
\hline & Extrathecal shunt & $\begin{array}{l}\text { Technically easy } \\
\text { Restoration of CSF flow outside the dural sac }\end{array}$ & Risk of shunt dysfunction or infection \\
\hline
\end{tabular}

CSF: cerebrospinal fluid

duraplasty can be curative and one of the best treatments because it resolves the main pathogenic factors responsible for syrinx formation and propagation. ${ }^{2,4,16,17)}$ Although several authors have reported good results, ${ }^{2,3,11,17-19)}$ its indication is limited to patients with focal arachnopathies since broad arachnoid dissection is technically difficult. ${ }^{14,17)}$ It is also restricted by the risk of spinal cord damage and the postoperative recurrence of adhesion ${ }^{12,13)}$ (Table 1). In this case, AA was too extensive to attempt arachnoidolysis.

Shunt placement is another one of the most common treatments as a CSF diversion procedure. ${ }^{4,20)}$ Shunt placement is selected when other causative treatments have failed or when arachnoidolysis is impossible due to extensive adhesion. Syringomyelia with extensive AA is mainly treated with this procedure. ${ }^{2,3)}$ Various shunt procedures, such as subarachnoid-subarachnoid, syringe-subarachnoid, syringe-pleural, and syringe-peritoneal, have been reported. ${ }^{2,5,13,14,17,21)}$ Shunt surgery can be categorized into intrathecal shunt and extrathecal shunt. Intrathecal shunt includes subarachnoid-subarachnoid and syringe-subarachnoid shunting, with the intent of restoring CSF flow in the dural sac. Extrathecal shunt includes syringe-pleural and syringe-peritoneal shunting and can achieve CSF drainage (Table 1). The type of shunt procedure is selected based on patient findings. There are few articles in which these various shunt surgeries have been compared directly, however, ${ }^{6)}$ and the criteria for the selection of the type of shunt procedure have not been well studied.

Although the patient's symptoms improved temporarily, they recurred within a relatively short period. As there were no obvious intraoperative events such as blood contamination, the reason for recurrence within a short period was speculated to be an insufficiency of non-affected subarachnoid space. A syringe-subarachnoid shunt and a subarachnoidsubarachnoid shunt were placed in the first operation to allow CSF to communicate freely in the intrathecal intact subarachnoid spaces and syrinx. Although drained CSF needed to be well managed by the intact subarachnoid space for our first surgery to be successful, it is quite difficult to predict whether or not this will occur. On the other hand, a syringe-peritoneal shunt which was emplaced in the second surgery can achieved the restoration of CSF drainage outside the dural sac. Its effect may be easier to predict than that of an intrathecal shunt in extensive AA (Table 1). Scarring from surgery for AA can result in additional AA and make the syrinx firm. Therefore, multiple surgeries contribute to the perpetuation of a syrinx cavity ${ }^{22)}$ and should be avoided if possible. Although syringo-peritoneal shunt drainage may have a relatively high risk of shunt dysfunction or infection ${ }^{4)}$ and be considered a further step in the treatment of syringomyelia, ${ }^{22)}$ a syringoperitoneal shunt may be a first-surgery option of the first surgery for syringomyelia due to extensive $\mathrm{AA}$, as was seen in this case.

To date, no established definition of extensive AA exists. MRI findings, such as central clumping of the nerve roots in the dural sac, peripheral adhesions and tethering of nerve roots, pial and dural enhancement, an enlarged central canal, and altered CSF and spinal cord signal, indicate AA. ${ }^{23)}$ AA with such MRI findings that exceeds two spinal segments has been termed as "extensive" AA because it is related to a worse long-term postoperative outcome. ${ }^{2}$ This definition is a reasonable one. In this study, shunt surgery was selected only in 1 out of 92 cases. ${ }^{2)}$ Although the long-term outcome of shunt surgery has yet to be reported, a syringe-peritoneal shunt may be worth considering for the first surgery if AA exceeds two spinal segments.

It is of note that these considerations are based on only a single case and the follow-up period may not be sufficient. A further study would be helpful to establish criteria for shunt procedure selection. Nevertheless, considering that syringomyelia due 
to $\mathrm{AA}$ is a rare disease and that each case is quite unique, we believe that insight from a case report is also valuable.

In the second operation, a shunt valve was placed because it may be helpful to adjust the amount of CSF drainage and to check if the tubes are clogged. Although there are several case reports in which shunt valves have been used for syringomyelia, ${ }^{2,4,15,24)}$ limited research has been carried out to evaluate their usefulness. ${ }^{25)}$ In addition, the valves are not designed for this purpose. Nevertheless, we think that valve implantation is worth considering in syringo-peritoneal shunt surgery as over-drainage has been reported to result in serious complications. ${ }^{22)}$

\section{Conclusion}

We reported a case of syringomyelia due to extensive AA. It is difficult to determine whether the intrathecal shunt is effective because it is impossible to know whether or not drained CSF can be managed within the intrathecal region. Syringo-peritoneal shunt may be a viable first-surgery option for syringomyelia due to extensive AA.

\section{Patient Consent}

The parents of the patient have consented to the submission of the case report for submission to the journal.

\section{Conflicts of Interest Disclosure}

None.

\section{References}

1) Brammah TB, Jayson MI: Syringomyelia as a complication of spinal arachnoiditis. Spine (Phila Pa 1976) 19: 2603-2605, 1994

2) Klekamp J: Treatment of syringomyelia related to nontraumatic arachnoid pathologies of the spinal canal. Neurosurgery 72: 376-389; discussion 389, 2013

3) Batzdorf U: Primary spinal syringomyelia. Invited submission from the joint section meeting on disorders of the spine and peripheral nerves. March 2005. J Neurosurg Spine 3: 429-435, 2005

4) Lam S, Batzdorf U, Bergsneider M: Thecal shunt placement for treatment of obstructive primary syringomyelia. J Neurosurg Spine 9: 581-588, 2008

5) Cacciola F, Capozza M, Perrini P, Benedetto N, Di Lorenzo N: Syringopleural shunt as a rescue procedure in patients with syringomyelia refractory to restoration of cerebrospinal fluid flow. Neurosurgery 65: 471-476; discussion 476, 2009
6) Takayasu M, Shibuya M, Kouketsu N, Suzuki Y: Rapid enlargement of a syringomyelia cavity following syringo-subarachnoid shunt: case report. Surg Neurol 45: 366-369, 1996

7) Iwasaki Y, Koyanagi I, Hida K, Abe H: Syringosubarachnoid shunt for syringomyelia using partial hemilaminectomy. Br J Neurosurg 13: 41-45, 1999

8) Koyanagi I, Iwasaki Y, Hida K, Houkin K: Clinical features and pathomechanisms of syringomyelia associated with spinal arachnoiditis. Surg Neurol 63: 350-355; discussion 355-356, 2005

9) Werner C, Mathkour M, Scullen T, Dallapiazza RF, Dumont AS, Maulucci CM: Recurrent arachnoid cysts secondary to spinal adhesive arachnoiditis successfully treated with a ventriculoperitoneal shunt. Clin Neurol Neurosurg 194: 105835, 2020

10) Isu T, Iwasaki $Y$, Akino $M$, Abe H: Surgical treatment of syringomyelia. Selection of surgical procedures. Neurol Med Chir (Tokyo) 29: 728-734, 1989

11) Klekamp J, Batzdorf U, Samii M, Bothe HW: Treatment of syringomyelia associated with arachnoid scarring caused by arachnoiditis or trauma. J Neurosurg 86: 233-240, 1997

12) Fujiwara $Y$, Manabe $H$, Izumi $B$, Shima $T$, Adachi N: Microscope and fiberscope-assisted subarachnoidsubarachnoid (S-S) bypass: a novel surgical technique to reestablish cerebrospinal fluid flow in treating dorsal spinal arachnoid webs, diagnosed by cine-MRI. Clin Spine Surg 31: 58-64, 2018

13) Iwatsuki K, Yoshimine T, Ohnishi $Y$, Ninomiya $K$, Moriwaki T, Ohkawa T: Syringomyelia associated with spinal arachnoiditis treated by partial arachnoid dissection and syrinx-far distal subarachnoid shunt. Clin Med Insights Case Rep 7: 107-110, 2014

14) Tachibana $T$, Moriyama $T$, Maruo K, Inoue $S$, Arizumi F, Yoshiya S: Subarachnoid-subarachnoid bypass for spinal adhesive arachnoiditis. J Neurosurg Spine 21: 817-820, 2014

15) Chang HS, Joko M, Matsuo N, Kim SD, Nakagawa H: Subarachnoid pressure-dependent change in syrinx size in a patient with syringomyelia associated with adhesive arachnoiditis. Case report. I Neurosurg Spine 2: 209-214, 2005

16) Shikata J, Yamamuro T, Iida H, Sugimoto M: Surgical treatment for symptomatic spinal adhesive arachnoiditis. Spine (Phila Pa 1976) 14: 870-875, 1989

17) Morisako H, Takami T, Yamagata T, Chokyu I, Tsuyuguchi N, Ohata K: Focal adhesive arachnoiditis of the spinal cord: imaging diagnosis and surgical resolution. J Craniovertebr Junction Spine 1: 100-106, 2010

18) Batzdorf U: Primary spinal syringomyelia: a personal perspective. Neurosurg Focus 8: E7, 2000

19) Holly LT, Johnson JP, Masciopinto JE, Batzdorf U: Treatment of posttraumatic syringomyelia with extradural decompressive surgery. Neurosurg Focus 8: E8, 2000

20) Kim SH, Choi SW, Youm JY, Kwon HJ: Syringosubarachnoid-peritoneal shunt using T-tube for treatment of post-traumatic syringomyelia. J Korean Neurosurg Soc 52: 58-61, 2012

NMC Case Report Journal Vol. 8, 2021 
21) Hirai T, Kato T, Kawabata S, et al.: Adhesive arachnoiditis with extensive syringomyelia and giant arachnoid cyst after spinal and epidural anesthesia: a case report. Spine (Phila Pa 1976) 37: E195-198, 2012

22) Batzdorf U, Klekamp J, Johnson JP: A critical appraisal of syrinx cavity shunting procedures. J Neurosurg 89: 382-388, 1998

23) Anderson TL, Morris JM, Wald JT, Kotsenas AL: Imaging appearance of advanced chronic adhesive arachnoiditis: a retrospective review. AJR Am J Roentgenol 209: 648-655, 2017

24) Klekamp J: Treatment of posttraumatic syringomyelia. J Neurosurg Spine 17: 199-211, 2012
25) Naito K, Yamagata T, Ohata K, Takami T: Safety and efficacy of syringoperitoneal shunting with a programmable shunt valve for syringomyelia associated with extensive spinal adhesive arachnoiditis: technical note. World Neurosurg 132: 14-20, 2019

Corresponding author: Kyohei Kin, MD, PhD Department of Neurological Surgery, Okayama University Graduate School of Medicine, 2-5-1 Shikatacho, Kita-ku, Okayama, Okayama 700-8558, Japan. e-mail: thekinkorea@gmail.com 